\title{
Obesity Increases Operating Room Times In Patients Undergoing Primary Hip Arthroplasty: A Retrospective Cohort Analysis
}

Background: Obesity impacts utilization of healthcare resources. The goal of this study was to measure the relationship between increasing body mass index (BMI) in patients undergoing total hip arthroplasty (THA) with different components of operating room (OR) time. Methods: The Stanford Translational Research Integrated Database Environment (STRIDE) was utilized to identify all ASA PS 2 or 3 patients who underwent primary THA at Stanford Medical Center from February 1, 2008 through January 1, 2013. Patients were divided into five groups based on the BMI weight classification. Regression analysis was used to quantify relationships between BMI and the different components of total OR time. Results: 1332 patients were included in the study. There were no statistically significant differences in age, gender, height, and ASA PS classification between the BMI groups. Normal-weight patients had a total OR time of 138.9 mins compared 167.9 mins $(P<0.001)$ for morbidly obese patients. At a BMI $>35 \mathrm{~kg} / \mathrm{m} 2$ each incremental BMI unit increase was associated with greater incremental total OR time increases. Conclusion: Morbidly obese patients required significantly more total $O R$ time than normal-weight patients undergoing a THA procedure. This increase in time is relevant when scheduling obese patients for surgery and has an important impact on health resource utilization. 
21 Stanford, CA 94305

\section{2}

${ }^{*}$ Corresponding author: Jay B. Brodsky, Department of Anesthesiology, Perioperative and Pain Medicine, H3580 Stanford University Medical Center, Stanford, CA 94305; Phone: (650) 725-65869; Fax: (650) 725-8544; Email: Jbrodsky@stanford.edu

${ }^{1}$ Department of Anesthesiology, Perioperative and Pain Medicine Stanford University Medical Center

Stanford, CA 94305

2 Department of Orthopaedic Surgery

Hospital of the University of Pennsylvania

3400 Spruce Street, 2 Silverstein

Philadelphia, PA 19104

\section{${ }^{3}$ Stanford University Economics Department} 579 Serra Mall

Attribution: Department of Anesthesiology, Perioperative and Pain Medicine, Stanford University Medical Center

27 Presentations: Abstract Poster Presentation at the Western Anesthesia Regional 28 Conference in Albuquerque, NM on May $10^{\text {th }} 2013$

29 Keywords: Obesity; Body mass index; Healthcare; Arthroplasty, replacement, hip. 30 Introduction: Using the World Health Organization's (WHO) weight-class definitions, two-thirds

32 of the adult population in the United States above the age of 60 years are "pre-obese" or 
33 "obese".[WHO, 2000; Flegal KM, et al. 2010] Furthermore, the prevalence of obesity is

34 projected to increase by $>33 \%$ over the next twenty years.[Finkelstein EA, 2012] The

35 current obesity "epidemic" has had a great impact on healthcare resources, and its

36 effects will increase further as the incidence of obesity continues to rise.[Wolf AM \&

37 Colditz, GA 1998; Allison DB, Zannolli R \& Narayan KM, 1999] In addition to an

38 increased risk of postoperative complications, hospital readmission rates are increased

39 for obese patients.[Farkas DT, et al. 2012; Reinke CE, et al. 2012] There is evidence

40 that the duration of certain surgical procedures and the total amount of time spent in the

41 operating room (OR) are also increased for obese patients.[Batsis JA, et al. 2009; Wang

$42 \mathrm{JL}$, et al. 2013] This is relevant since longer OR times can be extrapolated to an

43 increase in resource expenditures. Previous research has been conducted looking at the

44 increases in direct cost and length of stay in total hip arthroplasty.[Kremers HA, et al.

45 2014] For example, if not scheduled accurately, an operation running later than planned

46 will increase the potential need for overtime help.[Hirose K, et al. 2011] The increased

47 costs associated with the obese surgical patient are not accompanied by similar

48 increases in third party payments thereby placing financial risk on facilities that care for

49 these patients.[Silber JH, et al. 2012]

50 The goal of this study was to measure the relationship between increasing

51 obesity in patients undergoing total hip arthroplasty (THA) with the various components

52 of OR time in order to determine how obesity contributes to overall case duration. The

53 expected result is an increase in resource utilization for obese surgical patients as

54 measure by perioperative times.

\section{Materials and Methods:}


56 Following IRB approval, the Stanford Translational Research Integrated Database

57 Environment (STRIDE) was utilized to identify all patients who underwent primary THA

58 at Stanford Medical Center from February 1, 2008 through January 1, 2013. STRIDE is

59 a standards-based informatics platform supporting clinical and translational research

60 and includes a clinical data warehouse based on the HL7 Reference Information Model.

61 [Lowe HJ, et al. 2009] This observational research study utilized the STROBE guidelines

62 for improved reporting of the findings.[von Elm E, et al. 2008]

63 Only American Society of Anesthesiologists Physical Status (ASA PS) class 2 or 3

64 patients undergoing primary elective unilateral THA procedures under general

65 anesthesia, with or without spinal for post-operative pain control were included in the

66 study. ASA 1, 4 and 5 patients were removed from the study since they represent a

67 small number of the total hip arthroplasties. Patients were divided into five groups based

68 on WHO BMI classification.[WHO 2000] Group 1- normal-weight (BMI = 18.5-24.9

$\left.69 \mathrm{~kg} / \mathrm{m}^{2}\right)$, Group 2 - pre-obese $\left(\mathrm{BMI}=25-29.9 \mathrm{~kg} / \mathrm{m}^{2}\right)$, Group 3 - obese $(\mathrm{BMI}-30-34.9$

$70 \mathrm{~kg} / \mathrm{m} 2)$, and Group 4 - severely obese $\left(\mathrm{BMI}=35-39.9 \mathrm{~kg} / \mathrm{m}^{2}\right)$ and Group 5 - morbidly

71 obese $\left(B M I>=40.0 \mathrm{~kg} / \mathrm{m}^{2}\right)$.

72 The following parameters were retrieved: age, gender, height, weight, surgeon

73 (14 surgeons), anesthesiologist (116 anesthesiologists) and ASA PS. Patients who had

74 placement of central lines or arterial lines were excluded from the study since these

75 interventions could be a confounding variable for increased length of perioperative time.

76 Time stamps were retrieved from the STRIDE database. The data points

77 collected were time of (a) Admission to pre-op Unit, (b) Entry into operating room, (c)

78 Anesthesia handoff, (d) Surgery start, (e) Surgery end, (f) Out of operating room, (g)

79 Post-Anesthesia Care Unit (PACU) admission, (h) PACU discharge, and (i) Hospital 80 discharge day and time. 
81 The primary outcome variable of the study was total OR Time, which is the time

82 interval beginning when a patient entered the OR (b) until the moment the patient

83 physically left the OR (f).

84 Secondary outcome variables included:

85 1. Induction Time defined as the time from Entry into OR (b) to Anesthesia Handoff 86 (c). (Anesthesia handoff is the time the anesthesiologist completed his/her work 87 and turned the patient over to the surgical team for positioning, preparation, and 88 draping).

2. Operation time defined as the interval from Surgery Start (d) to Surgery End (e).

3. Emergence Time defined as the interval from Surgery End (e) to Out of Operating Room (f).

4. Recovery Room Time defined as the interval from PACU Admission (g) to PACU Discharge (h).

5. Total Hospital Length of Stay defined as the interval from the Admission to Pre-op

97 pre-operative, operating, and recovery room nurses who were unaware of study, as data 98 was analyzed retrospectively.

Statistical Analysis:

100 Observations taken from the STRIDE database, which already excluded patients

101 based on ASA, central line and/or arterial line placement, and regional anesthesia,

102 resulted in 1,613 patients. The top $1 \%$ and bottom $1 \%$ times for each data interval were

103 excluded as a means of removing incorrectly entered data points and ensuring outliers

104 did not drive the results (185 patients removed). Patients with a BMI of greater than 50 
$105 \mathrm{~kg} / \mathrm{m}^{2}$ or less than $18.5 \mathrm{~kg} / \mathrm{m} 2$ were removed from the study due to a paucity of data

106 points(96 patients removed). These two procedures would cause a wide variability in

107 induction times and could be representative of in ability to get a non-invasive blood

108 pressure or peripheral intravenous access or could be due to severity of illness. By

109 removing these few occurrences from our dataset, we reduce the possibility of variability

110 due to covariates and had a total of 1332 patients remaining. All data points for the time

111 intervals were available for these patients, except 1 was missing for induction time (1331

112 observations), 4 were missing for operation time (1328 observations), and 568 were

113 missing for recovery time (764 observations). The patients were grouped by body

114 mass index as defined by the WHO classifications (stated above in this section). For the

115 primary and each secondary outcome variable the mean and standard deviations were

116 calculated. We estimated regression parameters separately for each time component of

117 the case. In the data analysis BMI is an indicator variable. The database accessible

118 covariates that can affect case duration were included as regressors (e.g. patient age,

119 gender, height, and ASA PS classification) Table 5. These were included to remove any

120 variability in demographics, size, and severity of illness between our patient's in their

121 BMI groupings. Multiple t-test assuming unequal variance were performed to compare

122 the Group 1 (normal weight) BMI patients to each successively higher BMI grouping.

123 This analysis was repeated for the primary and each secondary outcome variables.

124 A graphical regression analysis was performed to quantify the relationship

125 between BMI $\left(\mathrm{kg} / \mathrm{m}^{2}\right)$ and total operating room time, induction time, total operation time,

126 emergence time, recovery room time, and length of hospital stay. Using Stata

127 (StataCorp LP, College Station, Texas) a kernel weighted local polynomial regression to

128 examine potential non-linearity in the relationship between BMI, the continuous variable,

129 and procedure duration was performed. In the graphical analysis the covariates are not 
130 controlled for. This method traces out average total OR time and induction time for each

131 BMI value without making any parametric assumptions.

\section{Results:}

133 A total of 1332 patients were included in this study. There were no statistically

134 significant differences in age, gender, height, and ASA PS classification between the 135 different study groups. Table 1

136 Group 1 (normal-weight) patients undergoing THA had a mean Total OR Time of

137138.9 mins, Group 3 (obese) patients 146.3 mins, and Group 5 (morbidly obese)

138 patients 167.9 mins. Table 2, Figure A The difference in mean times with adjusted and

139 unadjusted values are presented in Tables 3 and 4. Controlled values are presented in

140 Table 5.

141 There was also a direct association between increasing BMI and the length of

142 many of the individual components of total OR Time based on t-test between higher BMI

143 groups when compared to Normal BMI group. Incremental BMI group increase was

144 associated with a greater incremental time increase at higher BMls.

145 Patients in Group 1 had a mean Induction Time of 21.4 mins, Group 3 patients

14623.7 mins, while Group 5 patients required 28.2 mins. Figure B Group 5 patients had a

147 longer mean Operation Time of 103.0 mins versus 86.1 mins for Group1 patients.

148 Figure C For Group 1 patients, the mean Emergence Time equaled 9.1 mins compared

149 to 10.9 mins for Group 5. There were no statistically significant differences in mean 
150 Recovery Time between groups. Group 5 patients had a significant increased mean

151 Length of Hospital Stay, 3.9 days compared to 3.5 days for Group 1 patients. Table 2

\section{Discussion:}

153 As the number of obese patients continues to rise so does the demand for joint

154 arthroplasty procedures. Therefore, elucidating the impact of obesity on perioperative

155 costs is becoming ever more relevant.[Perka C, et al. 2000; Kurtz S, et al. 2007] Our

156 study of 1332 patients undergoing primary THA procedures at an academic medical

157 center found that obesity predictably lengthens both induction and surgical times. The

158 induction time is greater as expected due to longer times in moving, positioning, and

159 pre-oxygenating obese patients. The greatest single contributor to the increased

160 perioperative time requirements was the time needed by the surgeon to actually perform

161 the operation (Operation Time). Based on this information our facility has begun a pilot

162 project to schedule surgical time duration for THA cases by utilizing the difference in

163 mean time between patient's BMl using Table 3, Table 4 and Table 5, which provides

164 the absolute difference in mean time for each time interval when compared to a normal

165 weight patient and controls.

166 The reasons increasing weight lengthens both anesthesia and surgical times are

167 multifactorial but could be related to difficulties transferring patients to the OR table, with

168 airway management, with moving the patient to the lateral decubitus position once

169 anesthetized, and because excessive fat can interfere with intraoperative surgical

170 exposure. [Raphael IJ, et al. 2013] Obesity was not associated with longer recovery

171 time, probably because discharge from the recovery room is often dictated by non-

172 medical issues such as waiting for personnel to transport the patient to the ward or the

173 availability of a ward bed. 
174 It is estimated that by 2030, the number of primary THA operations will rise by

$175174 \%$, and a significant number of these patients will be obese.[Kurtz S, et al. 2007]

176 Health systems will have to absorb the additional financial burden of performing THA

177 procedures on obese patients. Those private orthopedic practices with a focus on

178 maintaining a predictable volume and minimizing costly complications may become

179 reticent in accepting obese patients. Besides the economic impact, the medical co-

180 morbidities associated with obesity pose management challenges for both surgeons and

181 anesthesiologists. With recent protocols penalizing health care providers for hospital

182 readmissions and postoperative complications, private practitioners may be less

183 incentivized to perform THA procedures on the obese. These factors all underscore that

184 public payer health systems may be required to absorb much of the financial

185 repercussions of increased resource utilization for obese surgical patients.

186 Throughout the US there is wide variability reported for actual operating room

187 costs depending on whether fixed costs or variable costs are included and on the

188 specific resources consumed by each patient.[Shippert R, 2005; Macario A, 2010]

189 Besides the increased operating room time costs attributable to obesity, our study also

190 noted expensive increased postoperative hospital length of stay. In addition, other

191 studies have also shown that obese patients have a higher rate of prosthesis failure, hip

192 dislocations, and wound infection.[Perka C, et al. 2000; Sadr AO, et al. 2008] Currently

193 pay-for-performance policies do not take into account obesity as a cause for increased

194 costs in the perioperative setting.[Hirose K, et al. 2011; Dowsey MM, Liew D \& Choong

195 PFM, 2011] Some facilities may choose not to operate on the morbidly obese unless

196 reimbursement is changed, especially if hospitals are penalized for readmissions under

197 changing health policy regulations. We believe it would be worthwhile to evaluate the

198 usefulness of a comprehensive protocol approach to the care of the morbidly obese 
199 surgical patient to ensure that appropriate pre-habilitation, proper equipment,

200 experienced nurses, and other resources are allocated to these patients.

201 In our analysis, the mean operation and induction times plateau and begin to

202 decrease as the extremes of BMI are reached. The confidence interval widens as the

203 BMI increases, which is a result of a limited number of morbidly obese patients

204 undergoing hip arthroplasty as compared to normal BMI, overweight, and obese patients

205 undergoing this operation.

206 This study has inherent limitations in the fact that it is a single-center

207 retrospective electronic chart-review. The time points collected by preoperative, OR, and

208 recovery room nurses may have some errors, but should affect the BMI groups similarly.

209 In the case of recovery times, a large number of the entered values were not recorded

210 by the STRIDE database properly limiting the power of our recovery time results. The

211 multiple t-test analysis is an inherent limitation in that we can only view each t-test alone,

212 since there is inherent correlation between time intervals. We decided to report the most

213 straightforward and easily understood test in the presentation of the data. Despite this, it

214 is apparent from the data presented that the higher the BMI the longer the OR time will

215 be. This will hold true however the data is reported. An inherent limitation in

216 retrospective non-randomized studies is the fact that causal inferences can be

217 mistakenly made, but we are confident in this study, which is supported by current

218 available literature. As can be seen in figure A and Figure B, the case time and

219 decreases slightly and the confidence interval widens. Outliers were removed as

220 mentioned above in the statistical analysis section. At the higher end of BMI there is a

221 paucity of data which leads to these potentially deceptive graphical representations. The

222 majority of total hip arthroplasties at our institution are performed under general

223 anesthesia, with or without spinal for post-operative pain control. At a majority of 
224 institutions across the country spinal anesthesia alone is the anesthetic plan of choice.

225 Despite this we believe that operation time and other secondary outcomes could be of 226 use.

227 Conclusion: We found that for patients undergoing THA, increasing BMI was

228 associated with increased total OR time. Also increasing BMI was associated with longer

229 hospital stays after THA. Operating room scheduling and plans for resource utilization

230 should recognize that the same THA procedure will require more time in a morbidly

231 obese patient than in a normal-weight or pre-obese patient. These considerations can

232 potentially reduce the increased healthcare costs associated with performing surgery on 233 obese patients. 


\section{Acknowledgments:}

235 We wish to acknowledge the contribtuions of Annie Katz, MD, Resident, Internal

236 Medicine, Stanford University Medical Center, Stanford, CA, USA for critical analysis of

237 the proposal and manuscript, Pietro Tebaldi, PhD, Stanford University, Stanford, CA,

238 USA for aiding in data analysis, and John Brock-Utne, MD, Professor of Anesthesiology,

239 Department of Anesthesiology, Perioperative and Pain Medicine, Stanford University

240 Medical Center, Stanford, CA, USA for critical analysis of the abstract. 


\section{References:}

242 1. Allison DB, Zannolli R \& Narayan KM. 1999. The direct health care costs of

243 obesity in the United States. American Journal of Public Health; 89:1194-9.

244 2. Batsis JA, Naessens JM, Keegan MT, Wagie AE, Huddleston PM, Huddleston

245 JM. 2009. Impact of body mass on hospital resource use in total hip arthroplasty.

246 Public Health Nutrition 12:1122-32.

247 3. Dowsey MM, Liew D \& Choong PFM. 2011. Economic burden of obesity in 248 primary total knee arthroplasty. Arthritis Care \& Research 63:1375-81.

249 4. Farkas DT, Moradi D, Moaddel D, Nagpal K, Cosgrove JM. 2012. The impact of 250 body mass index on outcomes after laparoscopic cholecystectomy. Surgical $251 \quad$ Endoscopy 26:964-9.

252 5. Finkelstein EA, Khavjou OA, Thompson H, Trogdon JG, Pan L, Sherry B, Dietz 253 W. 2012. Obesity and severe obesity forecasts through 2030. American Journal 254 of Preventive Medicine 42:563-70.

255 6. Flegal KM, Carroll MD, Ogden CL, Curtin LR. 2010. Prevalence and trends in 256 obesity among US adults, 1999-2008. Journal of the American Medical 257 Association 303:235-41.

258 7. Hirose K, Shore AD, Wick EC, Weiner JP, Makary MA. 2011. Pay for obesity? 259 Pay-for-performance metrics neglect increased complication rates and cost for 260 obese patients. Journal of Gastrointestinal Surgery 15:1128-35. 
261 8. Kremers H, Visscher S, Kremers W, Naessens J, Lewallen D. 2014. Obesity

262 increases length of stay and direct medical costs in total hip arthroplasty. Clinical

263 orthopaedics and related research 472:1232-9.

264 9. Kurtz S, Ong K, Lau E, Mowat F, Halpern M. 2007. Projections of primary and 265 revision hip and knee arthroplasty in the United States from 2005 to 2030. The 266 Journal of Bone and Joint Surgery American 89:780-5.

267 10. Lowe HJ, Ferris TA, Hernandez PM, Weber SC. 2009. STRIDE--An integrated 268 standards-based translational research informatics platform. AMIA. Annual 269 Symposium Proceedings / AMIA Symposium AMIA Symposium 2009:391-5.

270 11. Macario A. 2010. What does one minute of operating room time cost? Journal of $271 \quad$ Clinical Anesthesia 22:233-6.

12. Perka C, Labs K, Muschik M, Buttgereit F. 2000. The influence of obesity on 273 perioperative morbidity and mortality in revision total hip arthroplasty. Archives of 274 Orthopaedic and Trauma Surgery 120:267-71.

275 13. Raphael IJ, Parmar M, Mehrganpour N, Sharkey PF, Parvizi J. 2013. Obesity and 276 operative time in primary total joint arthroplasty. The Journal of Knee Surgery $277 \quad 26: 95-100$.

278 14. Reinke CE, Kelz RR, Zubizarreta JR, Mi L, Saynisch P, Kyle FA, Even-Shoshan 279 O, Fleisher LA, Silber JH. 2012. Obesity and readmission in elderly surgical 280 patients. Surgery 152:355-62. 
281 15. Sadr AO, Adami J, Lindström D, Eriksson KO, Wladis A, Bellocco R. 2008. High

282 body mass index is associated with increased risk of implant dislocation following

283 primary total hip replacement: 2,106 patients followed for up to 8 years. Acta

284 Orthopaedica 79:141-7.

285 16. Shippert R. 2005. A Study of Time-dependent Operating Room Fees and How to 286 Save $\$ 100,000$ by Using Time-Saving Products. Amercian Journal of Cosmetic

287 Surgery 22:25-34.

288 17. Silber JH, Rosenbaum PR, Kelz RR, Reinke CE, Neuman MD, Ross RN, Even-

289 Shoshan O, David G, Saynisch PA, Kyle FA, Bratzler DW, Fleisher LA. 2012.

290 Medical and financial risks associated with surgery in the elderly obese. Annals of 291 Surgery 256:79-86.

292 18. von Elm E, Altman D, Egger M, Pocock S, Gotzsche P, Vandenbroucke J. 2008.

293 The strengthening the reporting of oberservational studies in epidemiology

294 (STROBE) statement: guidelines for reporting observational studies. Journal of

$295 \quad$ Clinical Epidemiology 61:344-9.

296 19. Wang JL, Gadinsky NE, Yeager AM, Lyman SL, Westrich GH. 2013. The

297 Increased Utilization of Operating Room Time in Patients with Increased BMI

298 during Primary Total Hip Arthroplasty. The Journal of Arthroplasty 28:680-3.

299 20. WHO. Obesity: preventing and managing the global epidemic. Report of a WHO 300 consultation. World Health Organization Technical Report Series 2000. 894:i-xii, $301 \quad 1-253$. 
302 21. Wolf AM \& Colditz GA. 1998. Current estimates of the economic cost of obesity in 303 the United States. Obesity Research 6:97-106. 


\section{Table 1 (on next page) \\ Demographic variables}

Table 1: Demographic variables - associated standard deviation (when appropriate) and pvalue Comparing Normal BMI to other BMI Groupings. 


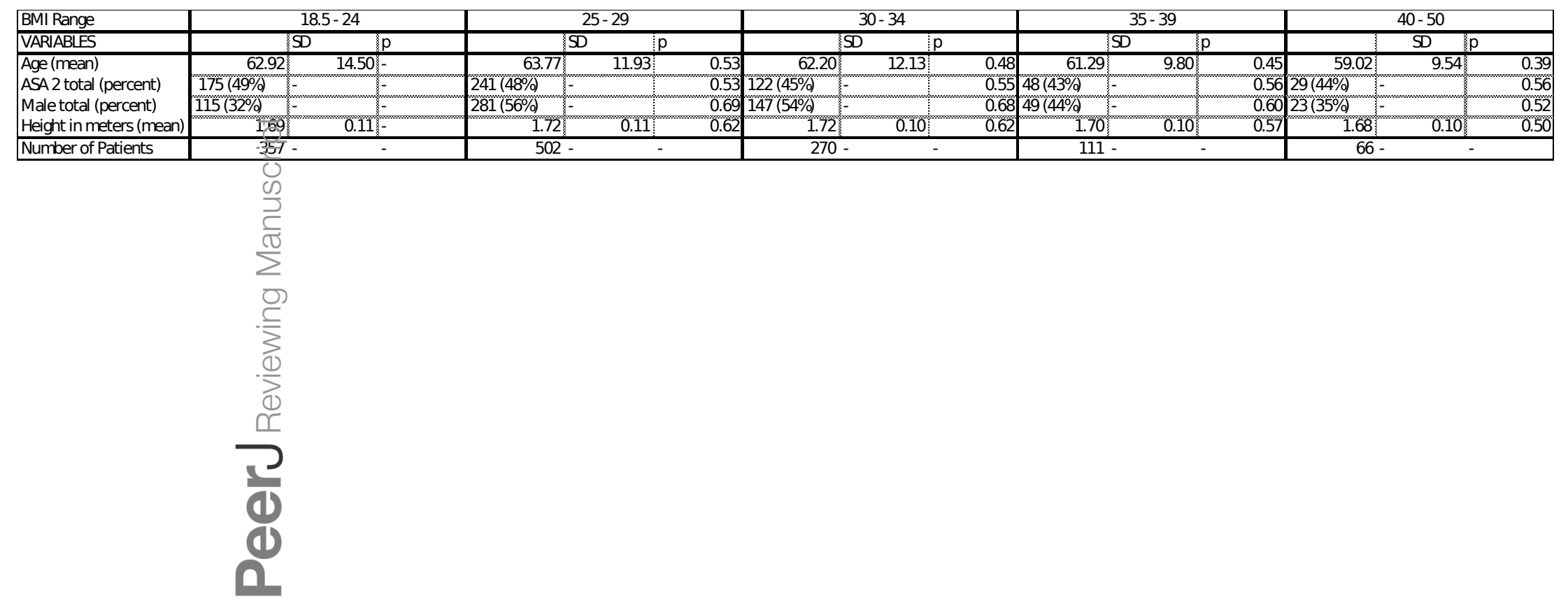




\title{
Table 2 (on next page)
}

Outcomes Table

\begin{abstract}
Table 2: Outcomes Table (Mean-listed in minutes except Total Hospital Time, standard deviation (SD), p-value: heteroscedastic T-Test Results Comparing Interval Times of Normal $\mathrm{BMI}$ to other BMI Groupings)
\end{abstract}




\begin{tabular}{|c|c|c|c|c|c|c|c|c|c|c|c|c|c|c|c|c|}
\hline BMI Range & \multicolumn{3}{|c|}{$18.5-24.9$} & \multicolumn{3}{|c|}{$25-29.9$} & \multicolumn{3}{|c|}{$30-34.9$} & \multicolumn{3}{|c|}{$35-39.9$} & \multicolumn{3}{|c|}{$40-50$} & \\
\hline VARIABLES & Mean & SD & $\mathrm{p}$ & Mean & $\mathrm{SD}$ & $\mathrm{p}$ & Mean & $\mathrm{SD}$ & $\mathrm{p}$ & Mean & SD & $\mathrm{p}$ & Mean & $\mathrm{SD}$ & $\mathrm{p}$ & Total Number \\
\hline$\overline{T \text { Total Time in OR }}$ & 138.9 & 1.4 & - & 141.7 & 1.2 & 0.152 & 146.3 & 1.8 & $<0.001$ & 156.3 & 2.9 & $<0.0005$ & 167.9 & 3.8 & $<0.0005$ & 1332 \\
\hline Induction Time & 21.4 & 0.4 & - & 21.8 & 0.4 & 0.475 & 23.7 & 0.5 & $<0.001$ & 26.3 & 0.8 & $<0.0005$ & 28.2 & 1.1 & $<0.0005$ & 1331 \\
\hline Operation Time & 861 & 1.2 & - & 87.4 & $\overline{0.9}$ & 0.425 & 90.3 & 1.4 & 0.022 & 97.6 & 2.4 & $<0.0005$ & 103.0 & 2.9 & $<0.0005$ & 1328 \\
\hline Emergence Time & 9.10 & 0.3 & - & 9.1 & 0.2 & 0.921 & 9.2 & $\overline{0.3}$ & 0.784 & 9.5 & 0.4 & 0.452 & 10.9 & 0.7 & 0.006 & 1332 \\
\hline Recovery Time & $184 \div$ & $\overline{3.9}$ & - & 174.8 & 3.2 & 0.136 & 167.7 & 4.5 & 0.031 & 184.9 & $\overline{7.9}$ & $\overline{0.994}$ & 174.6 & 8.0 & 0.474 & 764 \\
\hline Total Hospital Stay (Days) & 3.55 & 0.1 & - & 3.5 & 0.1 & 0.801 & 3.5 & 0.1 & 0.949 & 3.6 & 0.1 & 0.233 & 3.9 & 0.1 & 0.001 & 1332 \\
\hline Number of Patients & 362 & - & - & 512 & - & - & 275 & - & - & 113 & - & - & 70 & - & - & 1332 \\
\hline
\end{tabular}

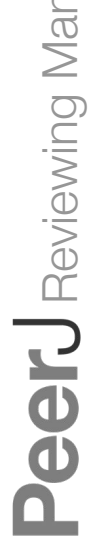




\section{Table 3 (on next page) \\ Adjusted Difference}

Table 3: Difference in mean times when compared to normal BMI patients (BMI 18.5-24.9), adjusted. 


\begin{tabular}{|c|c|c|c|c|c|c|c|c|c|c|c|c|c|}
\hline \multirow[t]{2}{*}{ BVII Range } & \multicolumn{3}{|c|}{$25-29.9$} & \multicolumn{3}{|c|}{$30-34.9$} & \multicolumn{3}{|c|}{$35-39.9$} & \multicolumn{3}{|c|}{$40-50$} & \multirow[b]{2}{*}{ Total Number } \\
\hline & Difference: & $95 \% \mathrm{Cl}$ & $\mathrm{p}$ & Difference & SD & $\mathrm{p}$ & Difference & SD & $\mathrm{p}$ & Difference; & SD & $\mathrm{p}$ & \\
\hline Total Time in OR & 3.48 & \pm 0.170 & 0.077 & 7.49 & \pm 0.268 & 0.001 & 16.89 & \pm 0.558 & $<0.001$ & 27.25 & \pm 0.859 & $<0.001$ & 1332 \\
\hline Induction Time & 0.38 & \pm 0.051 & 0.518 & 2.27 & \pm 0.080 & $<0.001$ & 4.87 & \pm 0.167 & $<0.001$ & 6.80 & \pm 0.258 & $<0.001$ & 1331 \\
\hline Operation Time & 02.03 & \pm 0.136 & 0.196 & 4.40 & \pm 0.215 & 0.016 & 11.15 & \pm 0.448 & $<0.001$ & 15.53 & \pm 0.686 & $<0.001$ & 1328 \\
\hline Emergence Time & $\frac{7}{(c)}-0.08$ & \pm 0.031 & 0.823 & 0.04 & \pm 0.046 & 0.914 & 0.33 & \pm 0.099 & 0.534 & 1.65 & \pm 0.151 & 0.011 & 1332 \\
\hline Recovery Time & 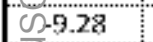 & \pm 0.587 & 0.171 & -16.23 & \pm 0.950 & 0.044 & -0.17 & \pm 1.567 & 0.987 & -12.59 & \pm 3.351 & 0.382 & 764 \\
\hline Total Hospital Stay (Days) & $=0.00$ & \pm 0.00 & 0.998 & -0.03 & \pm 0.011 & 0.780 & 0.18 & \pm 0.023 & 0.148 & 0.76 & \pm 0.036 & $<0.001$ & 1332 \\
\hline Total Number & 512 & & & 275 & & & 113 & & & 70 & & & 1332 \\
\hline
\end{tabular}

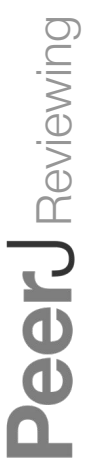




\section{Table 4 (on next page) \\ Unadjusted Difference}

Table 4. Difference in mean times when compared to normal BMI patients (BMI 18.5-24.9), unadjusted. 


\begin{tabular}{|c|c|c|c|c|c|c|c|c|c|c|c|c|c|}
\hline \multirow[t]{2}{*}{ BVII Range } & \multicolumn{3}{|c|}{$25-29.9$} & \multicolumn{3}{|c|}{$30-34.9$} & \multicolumn{3}{|c|}{$35-39.9$} & \multicolumn{3}{|c|}{$40-50$} & \multirow[b]{2}{*}{ Total Number } \\
\hline & Difference: & $95 \% \mathrm{Cl}$ & $\mathrm{p}$ & Difference; & $S D$ & $\mathrm{p}$ & Difference: & SD & $\mathrm{p}$ & Difference; & SD & $\mathrm{p}$ & \\
\hline Total Time in oR & 2.794 & \pm 0.169 & 0.153 & 7.435 & \pm 0.269 & 0.001 & 17.460 & \pm 0.565 & $<0.001$ & 28.980 & \pm 0.869 & $<0.001$ & 1332 \\
\hline Induction Time & 0.412 & \pm 0.050 & 0.475 & 2.286 & \pm 0.079 & $<0.001$ & 4.886 & \pm 0.167 & $<0.001$ & 6.825 & \pm 0.247 & $<0.001$ & 1331 \\
\hline Operation Time & 0.247 & \pm 0.135 & 0.425 & 4.163 & \pm 0.215 & 0.022 & 11.530 & \pm 0.455 & $<0.001$ & 16.940 & \pm 0.695 & $<0.001$ & 1328 \\
\hline Emergence Time & $\frac{1}{c} 0.339$ & \pm 0.133 & 0.921 & 0.108 & \pm 0.047 & 0.784 & 0.400 & \pm 0.098 & 0.534 & 1.761 & \pm 0.151 & 0.010 & 1332 \\
\hline Rercovery Time & C.9.984 & \pm 0.580 & 0.136 & -17.100 & \pm 0.936 & 0.031 & 0.077 & \pm 1.416 & 0.994 & -10.270 & +3.341 & 0.474 & 764 \\
\hline Total Hospital Stay (Days) & $=0.023$ & \pm 0.007 & 0.773 & -0.057 & \pm 0.011 & 0.550 & 0.167 & \pm 0.024 & 0.189 & 0.753 & \pm 0.036 & $<0.001$ & 1332 \\
\hline Number of Patients & (․ 512 & & & 275 & & & 113 & & & 70 & & & 1332 \\
\hline
\end{tabular}

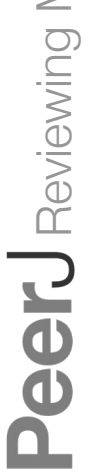




\section{Table 5 (on next page)}

Controls

Table 5 - Controls: difference in time points holding all other control variables constant. The Sex column is the difference in mean time between males and females with all other variables held constant. The Age column is the difference in mean time between an individual and another 1 year younger with all other variables held constant. The Height column is the difference in mean time between for an individual and another 1 inch shorter with all other variables held constant. The ASA column is the difference in mean time between ASA 3 and ASA 2 with all other variable held constant. 


\begin{tabular}{|c|c|c|c|c|c|c|c|c|c|c|c|c|c|}
\hline \multirow[t]{2}{*}{ BVII Range } & \multicolumn{3}{|c|}{ Sex } & \multicolumn{3}{|c|}{ Age } & \multicolumn{3}{|c|}{ Height } & \multicolumn{3}{|c|}{$A S \cap$} & \multirow[b]{2}{*}{ Total Number } \\
\hline & Difference: & SD & $\mathrm{p}$ & Difference; & SD & $\mathrm{p}$ & Difference: & SD & $\mathrm{p}$ & Difference; & $5 \mathrm{D}$ & $\mathrm{p}$ & \\
\hline Total Time in oR & 1.072 & \pm 0.186 & 0.620 & -0.372 & \pm 0.008 & $<0.001$ & -22.730 & \pm 1.862 & 0.024 & 3.430 & \pm 0.362 & 0.026 & 1332 \\
\hline Induction Time & 0.374 & \pm 0.056 & 0.564 & 0.009 & \pm 0.002 & 0.631 & -2.483 & +0.558 & 0.412 & 0.490 & +0.108 & 0.289 & 1331 \\
\hline Operation Time & Q. 383 & \pm 0.151 & 0.824 & -0.328 & \pm 0.006 & $<0.001$ & -20.520 & +1.484 & 0.011 & 1.794 & \pm 0.288 & 0.146 & 1328 \\
\hline Emergence Time & 0.443 & \pm 0.033 & 0.245 & -0.013 & \pm 0.001 & 0.247 & -2.067 & \pm 0.329 & 0.245 & 0.498 & \pm 0.064 & 0.067 & 1332 \\
\hline Recovery Time & $\sigma_{2} .490$ & \pm 0.674 & 0.748 & 0.255 & \pm 0.026 & 0.748 & -68.030 & \pm 6.780 & 0.065 & 8.572 & \pm 1.287 & 0.118 & 764 \\
\hline Total Hospital Stay (Days) & $=0.012$ & \pm 0.008 & 0.895 & 0.005 & \pm 0.000 & 0.039 & -0.925 & +0.0779 & 0.029 & 0.183 & \pm 0.015 & 0.005 & 1332 \\
\hline Total Number & (6) 512 & & & 275 & & & 113 & & & 70 & & & 1332 \\
\hline
\end{tabular}

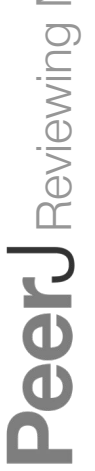




\section{Figure 1}

Total case time

Figure 1: Legend: Total Case time (patient in room to patient out of room in minutes) and BMI Polynomial Regression Line (blue line) with $95 \% \mathrm{Cl}$ (gray); (Epanechnikov kernel of degree 0 , Bandwidth of 3.24, pwidth of 4.86) $¥<$ !--[if !supportFootnotes]-->[b] $<!--[e n d i f]-->¥$ The differences in the bandwidth are due to differences in the variance of outcome variables.

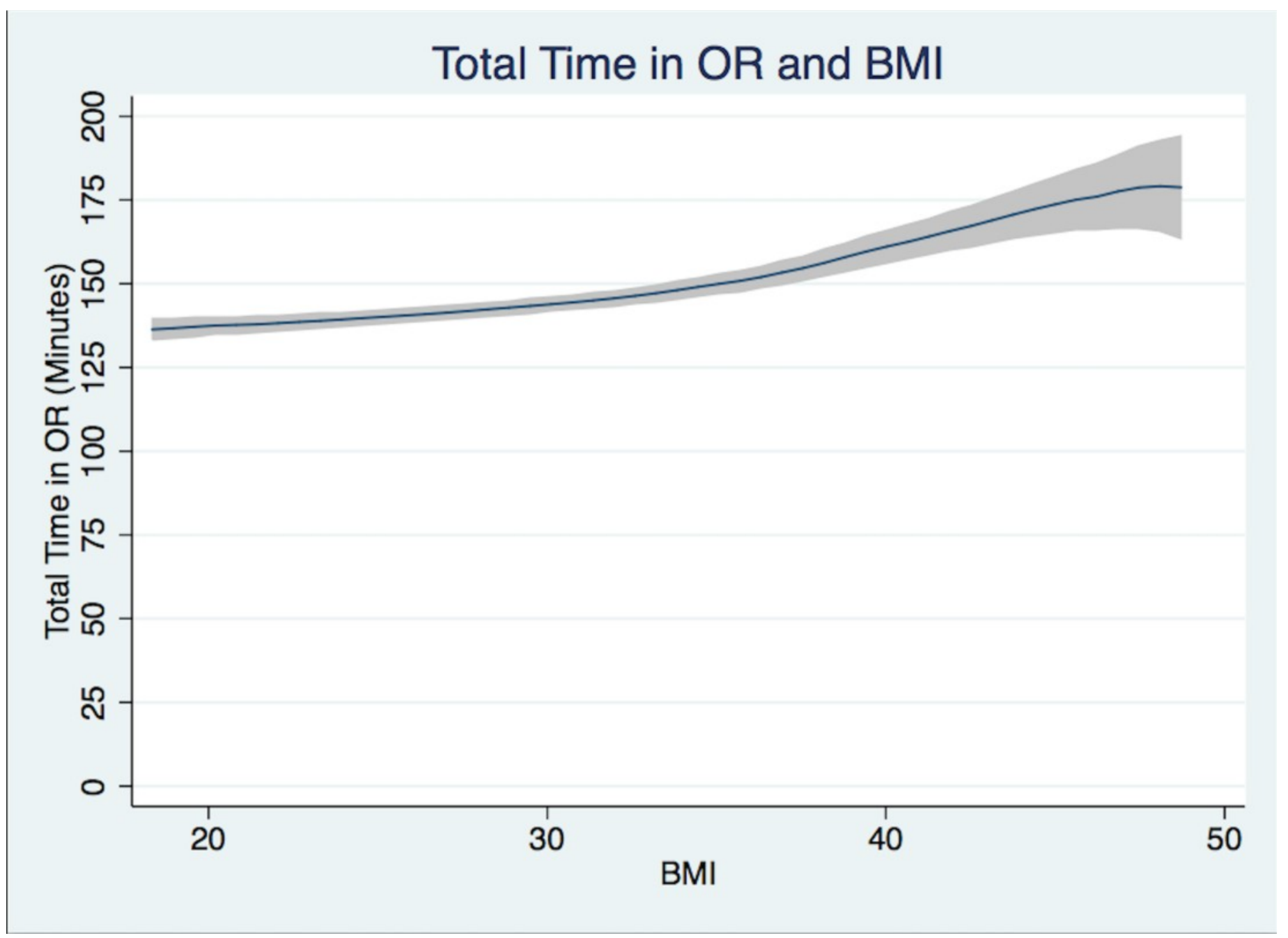




\section{Figure 2}

Induction time

Figure 2: Legend: Induction Time (from patient in room to handoff from anesthesiologist to surgeon in minutes) and BMI Polynomial Regression Line (blue line) with $95 \% \mathrm{Cl}$ (gray); (Epanechnikov kernel of degree 0, Bandwidth of 2.2, pwidth of 3.3) $¥<!--[$ if ! supportFootnotes]-- $>[b]<!--[e n d i f]-->¥$ The differences in the bandwidth are due to differences in the variance of outcome variables.

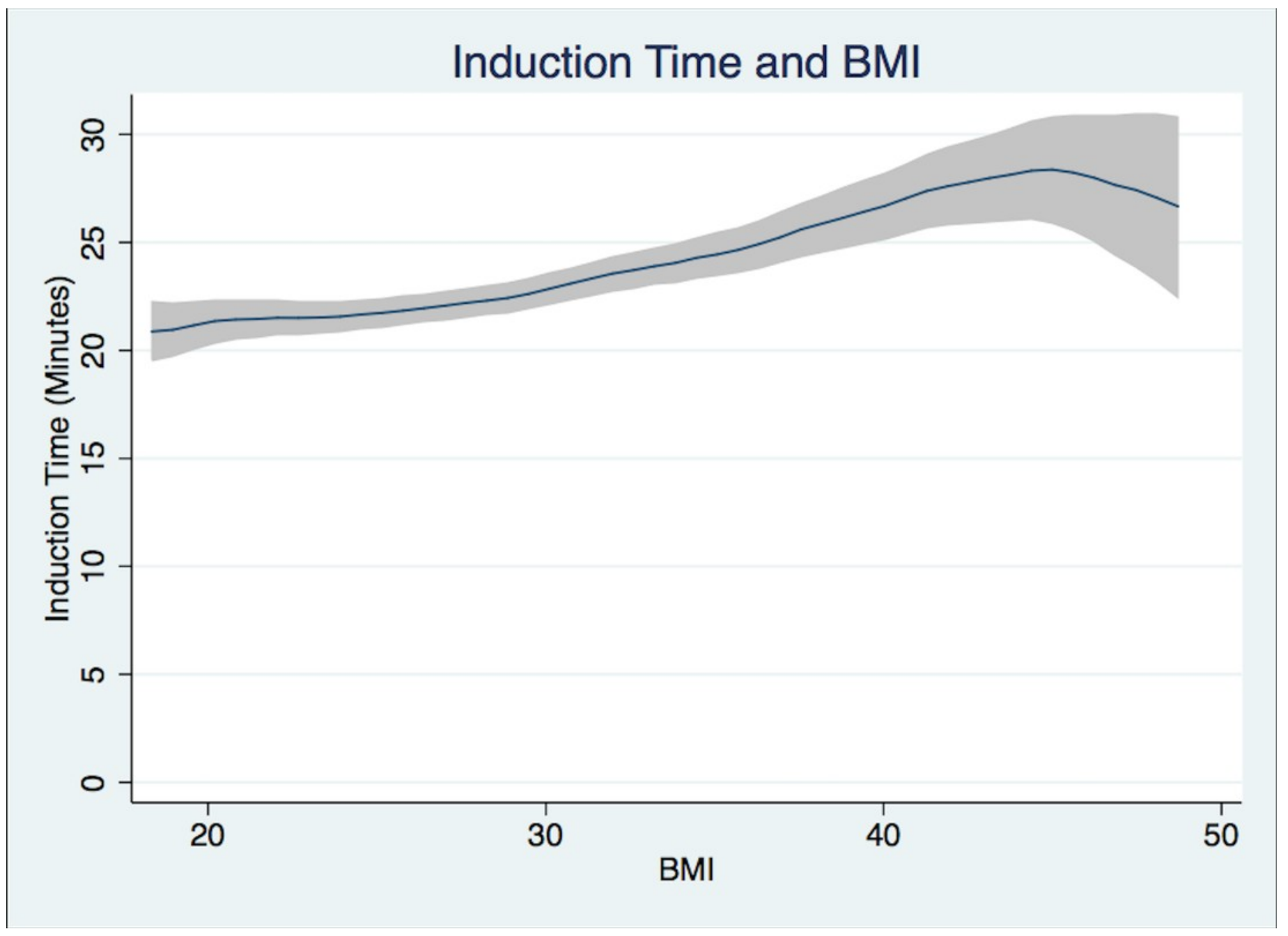




\section{Figure 3}

Operation time

Figure 3: Legend: Operation Time (from surgery start time to surgery end time in minutes) and BMI Polynomial Regression Line (blue line) with 95\% Cl (gray); (Epanechnikov kernel of degree 0 , Bandwidth of 3.02, pwidth of 4.53$) ¥<$ !--[if !supportFootnotes]-->[b] $<!--[$ endif]--> $¥$ The differences in the bandwidth are due to differences in the variance of outcome variables.

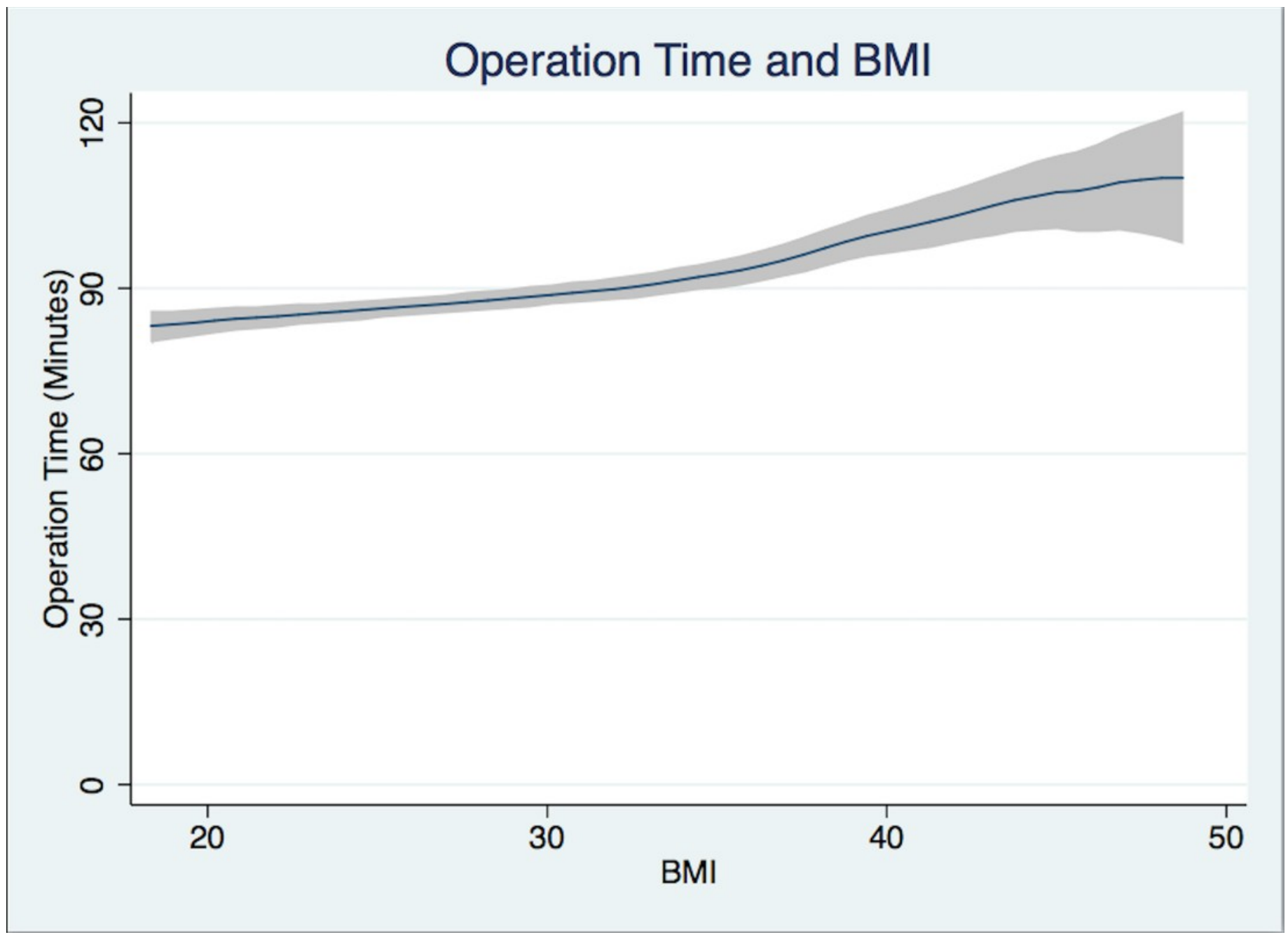

